\title{
Reparo Iniciado e Levado a Cabo pelo Outro na Conversa Cotidiana em Português do Brasil *
}

\author{
(Other-Initiated Other-Repair in Ordinary \\ Conversation in Brazilian Portuguese)
}

\author{
Pedro M. Garcez \\ Letícia Ludwig LODER \\ (UFRGS/CNPq)
}

\begin{abstract}
This is a research report on other-initiated other-repair in ordinary conversation conducted in Brazilian Portuguese. With the aim of investigating whether the organization of this repair trajectory in Brazilian Portuguese interaction matches that described for conversationalists interacting in North-American English, 15 hours of interaction were analyzed within the framework of Conversation Analysis. Despite minor differences in some practices, the trajectory is found to be as dispreferred in this corpus as it is in English interaction. Additionally, it was observed that the repaired participant is constrained to acknowledge the repair movement on his/her prior turn. $\boldsymbol{K} \boldsymbol{E} \boldsymbol{Y}$-WORDS: repair; conversation; correction; disagreement.

REsumo: Apresentam-se resultados de pesquisa sobre o reparo iniciado e levado a cabo pelo outro em interações cotidianas em portugues do Brasil. Com o intuito de verificar se a organização dessa trajetória de reparo se apresentaria conforme a descrição já consolidada dos fenomenos de reparo entre falantes de inglês norte-americano, 15 horas de gravação foram analisadas segundo a perspectiva teórico-metodológica da Análise da
\end{abstract}

\footnotetext{
* Este artigo resulta de trabalho de pesquisa apoiado pelo CNPq, sob a forma de bolsa de Produtividade em Pesquisa (Processos 551226/2002 e 503329/2004) ao primeiro autor e bolsa de mestrado à segunda autora, que recebeu apoio também da Propesq/UFRGS sob a forma de bolsa de IC (2001-2003). Agradecemos aos integrantes do grupo de pesquisa ISE (Interação Social e Etnografia), da Universidade Federal do Rio Grande do Sul, pela leitura, comentários e sugestões feitos a uma versão prévia deste documento. Eventuais equívocos que ainda restem são de nossa responsabilidade. As citações de textos em inglês aparecem ao longo do texto em português segundo nossa tradução informal para os fins deste artigo.
}

D.E.L.T.A., 21:2, $2005(279-312)$ 
Conversa Etnometodológica. Conclui-se que, na conversa em português brasileiro, ofenômeno também é raro e apresenta marcas de despreferência. Além disso, observamos que essas trajetórias de reparo pelo outro criam um constrangimento com o qual o participante reparado lida antes de a ação prosseguir.

PALAVRAS-CHAVE: reparo; conversa; correção; discordância.

\section{Introdução}

Apresentamos aqui os resultados de nosso trabalho de pesquisa sobre o fenômeno conversacional reparo iniciado e levado a cabo pelo outro (doravante RILCO) em conversas cotidianas cuja língua de interação é o português do Brasil. Nosso intuito foi verificar se a organização dessa trajetória de reparo na conversa cotidiana entre falantes de português brasileiro se apresentaria conforme a descrição já consolidada dos fenômenos de reparo em interações entre falantes de inglês norte-americano.

A perspectiva teórica que orienta o trabalho é a Análise da Conversa Etnometodológica ${ }^{1}$ (doravante ACE), tradição de pesquisa de extração sociológica que tem intensa interlocução com abordagens afins no âmbito dos estudos da linguagem. Compartilhando com outros domínios de saber o interesse pelo uso da linguagem, a ACE aborda esse objeto a partir de sua importância na constituição da ação nas sociedades humanas. O uso da linguagem é entendido não como mera manifestação de estruturas cognitivas mais profundas ou como a expressão das intenções de um falante. É, sim, concebido como elemento crucial na construção das ações sociais, pois é mediante o uso da linguagem que os membros de uma sociedade, a cada momento em que interagem, fazem coisas co-ordenadamente, constroem colaborativamente seus encontros, que, tomados em conjunto, formam o

\footnotetext{
1 A Etnometodologia, uma Sociologia Radical (Coulon 1995; Heritage 1987/1999), ainda tem pouca penetração nos departamentos de Sociologia no Brasil, o mesmo podendo ser dito da ACE, um dos mais notáveis desenvolvimentos da Etnometodologia. Embora alguns textos seminais da ACE tenham sido base de inspiração de estudos de Lingüística Textual sobre a língua falada no Brasil sob a rubrica de Análise da Conversação (Mascuschi 1986; Barros 1993), entendemos que há diferenças teóricas e metodológicas robustas o suficiente para que se faça a distinção entre a Análise da Conversação brasileira e a ACE. As duas tradições têm, cada uma, métodos e objetos de análise próprios, absolutamente legítimos e adequados para lidar com as questões de pesquisa às quais se propõem.
} 
que chamamos de sociedade e de história. Assim, entende-se que as interações são fruto de constante co-construção, em que o que conta é a coordenação entre os participantes em torno da ação conjunta, e não simplesmente suas ações individuais (Jacoby \& Ochs 1995; Clark 1996).

Todas as observações feitas pelos estudos fundadores da ACE, tanto sobre o sistema de tomada de turnos quanto sobre o sistema de reparo, tiveram por base dados de interação em inglês norte-americano. Isso tem motivado pesquisadores que trabalham com dados de fala-em-interação em outras línguas a investigar o funcionamento de aspectos daqueles sistemas nas interações de ocorrência naturalística em outras comunidades (por exemplo, Moerman, 1988; Egbert, 1997; Chui, 1996; Wong, 2000). Marcuschi (1986:21), ao comentar a descrição do sistema de tomada de turnos feita por analistas da conversa norte-americanos, afirmou: "Não é necessária muita perspicácia para constatar que, no Brasil pelo menos, as regras acima [do sistema de tomada de turnos] são sobejamente desrespeitadas. (...) não parece ser apenas uma questão de disciplina o desrespeito dos brasileiros: o mais provável é que por trás disso esteja um outro modelo cultural". Contudo, Schegloff (2000a:234 e 241) argumenta que há "um lugar sócio-interacional já moldado por uma série de estruturas de práticas que parecem transcender os limites culturais e lingüísticos de forma relativamente robusta" e que "a organização da tomada de turnos e do reparo, por exemplo, parecem, até agora, ser estáveis através dos limites lingüísticos e culturais e, ao mesmo tempo, adaptáveis a suas especificidades". É nesse debate que se insere o presente trabalho.

O trabalho que aqui se apresenta, então, é fruto de nosso engajamento na tendência de investigar como se dá a organização interacional em comunidades diferentes daquelas inicialmente investigadas por Sacks, Schegloff e Jefferson (no nosso caso, participantes que interagem em português brasileiro), e, ao observar as práticas e ações em torno do RILCO, queremos também averiguar se a descrição do sistema de reparo disponível na literatura internacional se mostra ou não "estável através dos limites lingüísticos e culturais" entre os interagentes em inglês norte-americano e em português brasileiro.

Para a análise a que nos propomos, após breve revisão das reflexões já publicadas sobre os fenômenos de reparo e correção, apresentamos ocorrências do fenômeno em foco para análise e discussão. Conclui-se que a ocorrência de RILCO em português brasileiro é rara e apresenta marcas de 
despreferência, destacando-se uma observação que não havia sido previamente referida na literatura internacional em ACE, que é o fato de o reparo pelo outro criar um constrangimento com o qual o participante reparado lida antes de a ação prosseguir.

\section{Referencial teórico}

Partindo da perspectiva de que a fala-em-interação apresenta organização sistemática que é passível de investigação científica e descrição, a ACE tem por objetivo articular os métodos e práticas recorrentes de que os interagentes se utilizam para constituir as ações sociais da vida cotidiana e institucional. As descrições estão sempre calcadas na observação de dados empíricos de fala-em-interação de ocorrência natural, registrados em áudio e/ou vídeo, o que permite um contínuo e repetido contato com os dados e uma reflexão detalhada acerca dos fenômenos sociais. Tem-se como foco privilegiado a perspectiva dos participantes no momento da interação, isto é, as questões para as quais os interagentes observadamente se orientam na construção das suas ações. Considerando-se que, na fala-eminteração, sobretudo na conversa cotidiana, os participantes estão continuamente demonstrando uns para os outros seus entendimentos quanto a o que estão fazendo, que por sua vez se tornam disponíveis também para observadores externos (no caso, os analistas), o que interessa para a análise são esses entendimentos revelados, demonstrados, pelos próprios participantes, uns para os outros, na sua inter-ação.

Também basilar é a noção de que a conversa cotidiana é o sistema elementar e fundador de fala-em-interação, da qual todos os outros tipos derivam, não por ser necessariamente igualitária, mas pela constatação de que é o uso da linguagem presente em todas as sociedades humanas, não requerendo quaisquer habilidades ou treinamento especial além da própria socialização inicial em um grupo humano, sendo também, portanto, o ambiente interacional em que se dá a própria aquisição da linguagem (Clark 1996; Schegloff 1999). Assim, as interações médico/paciente em uma clínica médica, juiz/depoente em um tribunal ou pesquisador/informante em uma entrevista sociolingüística, por exemplo, apresentam uma organização semelhante à da conversa, mas se constituem como institucionais pelas modificações observáveis em alguns aspectos que organizam a conversa cotidiana (Garcez 2002b), especialmente no que diz respeito à tomada 
de turnos e ao reparo, conforme se discute a seguir, segundo Sacks, Schegloff e Jefferson (1974) e Schegloff, Jefferson e Sacks (1977).

\section{Noções fundadoras}

Em seus estudos iniciais, hoje considerados clássicos, Harvey Sacks, Emanuel Schegloff e Gail Jefferson focalizaram sua investigação em dois sistemas que consideravam fundamentais na organização da fala-em-interação social: a tomada de turnos e o reparo. ${ }^{2}$ Com o intuito de articular as práticas recorrentes que observaram na alternância de turnos entre falantes no andamento de uma interação, publicaram, pela primeira vez em 1974, uma descrição do sistema de tomada de turnos. Essa descrição contempla e problematiza os elementos que compõem cada turno de fala, a relação entre a transição de turnos e os elementos constituintes dos próprios turnos, ressaltando a relevância da seqüencialidade dos turnos de fala para a constituição das ações. Não tratando propriamente de regras no sentido que o termo adquire em Fonologia ou Sintaxe, essa descrição trata de práticas (Schegloff 1992a, 1997a, 2000b) recorrentemente exploradas e gerenciadas a cada momento pelos próprios participantes na construção de suas interações.

Já naquele momento, em 1974, os autores mencionaram a existência de um outro conjunto de práticas, cuja organização seria paralela à da organização do sistema de tomada de turnos e que se constituía de mecanismos disponíveis para resolver problemas que surgem no andamento da fala-em-interação: as práticas de reparo. Inserido no funcionamento seqüencial da interação, nessa primeira abordagem, o fenômeno do reparo foi assim enquadrado: "As várias organizações que operam na conversa estão suscetíveis a erros, violações e problemas; e os mecanismos de reparo estão ao seu dispor [dessas organizações]" (Sacks, Schegloff \& Jefferson 1974:723). Pontualmente, em 1974, os autores centraram sua atenção nos "mecanismos [de reparo] dirigidos e projetados aos problemas de tomada de turno" (Sacks, Schegloff \& Jefferson 1974:723), mas deixaram claro que esse não seria o único tipo de problema interacional para o qual os participantes lançariam mão do sistema de reparo.

2 Além desses sistemas, também fundamental é a noção de adjacência, bastante mais divulgada em Lingüística (Levinson, 1983, Cap. 6). 
Alguns anos depois, Schegloff, Jefferson e Sacks (1977) publicaram uma descrição da organização do reparo, examinando mais detidamente seu funcionamento na conversa cotidiana. O fenômeno foi descrito como um recurso dirigido a resolver "problemas recorrentes de produção, escuta e entendimento" (1977:361) da fala-em-interação social. Desde o princípio, os autores esclareciam que o reparo não necessariamente se iguala à prática $^{3}$ da correção (entendida como substituição de um item considerado "errado" por outro considerado "correto"). O reparo se caracteriza sobretudo pela identificação (realizada pelos interagentes) de um problema interacional e alguma (tentativa de) resolução do mesmo, isto é, lidar com o problema se torna o negócio interacional em foco, sendo que, para tanto, pode haver uma suspensão ou interrupção das ações então em curso. Isso pode acontecer na ausência de "erro" (gramatical, por exemplo), como ocorre quando um interagente interrompe a produção de seu turno para procurar uma palavra (o nome de alguém, por exemplo) antes de prosseguir (nesse caso, o problema para os participantes é a falta do nome, e não algum erro que precise ser corrigido). Desse modo, a prática da correção (substituição de um item por outro) é entendida como um componente específico de certas trajetórias de reparo. ${ }^{4}$

Naquela descrição, os fundadores da ACE observaram que o reparo é primordialmente constituído de duas partes: a iniciação e o resultado. Isto é, na iniciação, se aponta que há um problema a ser resolvido, e, no resultado, o problema pode ser resolvido com sucesso ou pode resultar em abandono (quando, depois de terem iniciado reparo, os interagentes não conseguem resolver o problema, o que se configura como um resultado de fracasso). Estando atreladas à organização seqüencial da fala-em-interação, a iniciação e o resultado do reparo não ocorrem aleatoriamente em qualquer ponto da interação. A iniciação do reparo ocorre dentro de um espaço seqüencialmente restrito de oportunidades próximas à fonte de problema, conforme ilustram os excertos a seguir'

3 Para uma discussão acerca da sutil distinção entre prática e ação, crucial em ACE, ver Schegloff (1997a).

4 Cabe observar desde já que pode haver correção sem haver reparo, pois só há reparo quando o ato de apontar para um problema interacional se torna a atividade em foco (ver Jefferson 1987).

5 Os excertos apresentados nesta seção advêm de nosso acervo de gravações, que inclui interações institucionais, além das 15 horas de conversa cotidiana que serviram de dados para o estudo relatado neste artigo. 
a) antes do final da unidade de construção do turno ${ }^{6}$ que contém a fonte de problema;

Gabriela: porque ele ti- ele: : mexe: $u$ né nu:m,=

Nesse turno, Gabriela inicia a unidade de construção de turno porque ele ti-, que será suspensa antes de seu fim, iniciando reparo para incluir ele::: mexe::u né nu:m,.

b) no lugar relevante para a transição de turno;

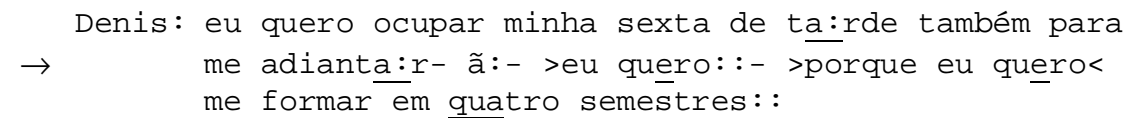

Nesse turno, a elocução de Denis eu quero ocupar minha sexta de tarde também para me adiantar poderia ser um turno completo, com unidade de construção de turno final completa. Entretanto, nesse ponto, em que é relevante a transferência de turno, Denis projeta uma nova unidade (ã:-eu quero::), que será alvo de iniciação de reparo a seguir, com porque eu quero.

c) no turno seguinte ao que contém a fonte de problema;

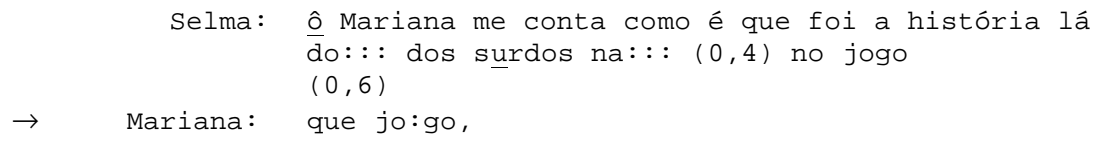

Nesse fragmento, a menção de Selma a no jogo é apontada como fonte de problema por sua interlocutora, que inicia reparo no turno seguinte com que jogo,.

d) ou no terceiro turno em relação à fonte de problema.

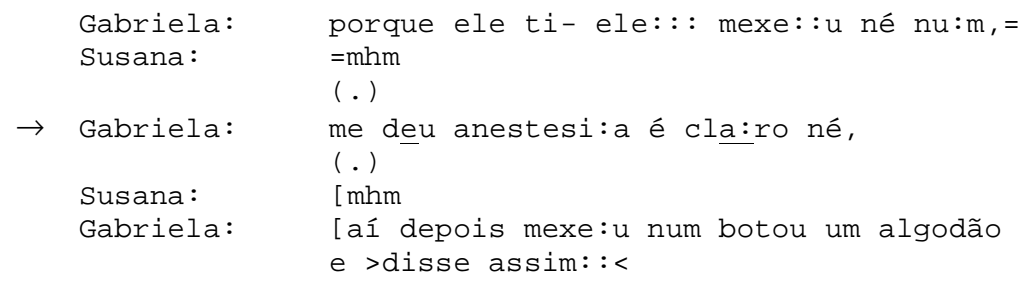

6 As noções de unidade de construção de turno e lugar relevante para a transição foram apresentadas em Sacks, Schegloff e Jefferson (1974) e mais extensamente discutidas em Schegloff (1996). Grosso 
Nesse fragmento, a unidade de construção projetada por Gabriela no primeiro turno com ele::: mexe::u né num, é suspensa (note-se que será retomada no último turno de Gabriela reproduzido no excerto com aí depois mexe:u num) para a introdução de me deu anestesi:a é cla:ro né, que só é produzido depois do turno da interlocutora Susana (o segundo na seqüência $-\mathrm{mbm}$ ).

Uma vez feita a iniciação, o resultado ocorre no mesmo turno da fonte de problema (como nos fragmentos apresentados nos itens a e b acima) ou nos turnos imediatamente seguintes (como no fragmento apresentado no item d acima). Cada um desses dois movimentos que compõem o reparo (iniciação e resultado) pode ser realizado tanto pelo falante da fonte de problema quanto pelo outro, seu interlocutor, sendo que vem a ser conseqüente - para o que está sendo feito - quem realiza cada movimento.

Assim, temos, em ordem de oportunidade de ocorrência, as seguintes trajetórias elementares de reparo ${ }^{7}$ :

i) reparo iniciado e levado a cabo pelo falante da fonte de problema (o falante interrompe a construção de seu turno e refaz parte do que disse);

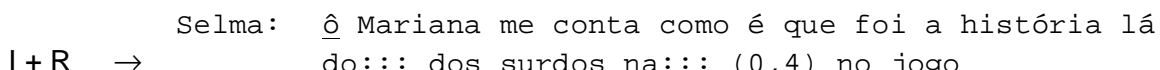

ii) reparo iniciado pelo falante da fonte de problema e levado a cabo pelo outro (por exemplo, o falante interrompe a produção de seu turno para procurar o nome de alguém sobre quem está falando, e o interlocutor produz um item que preenche essa lacuna);

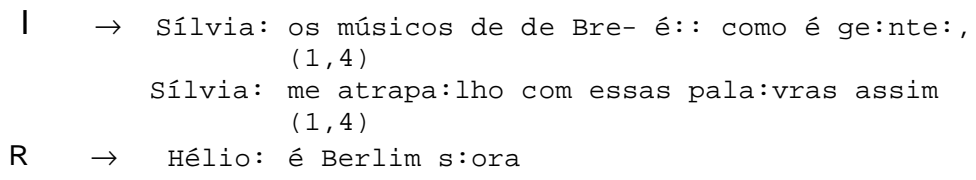

modo, são as unidades de que se compõem os turnos de fala, caracterizadas por completude sintática ou prosódica, e também por poderem ser analisadas, ao seu fim, como tendo implementado/implicado/feito uma ação (isto é, por serem analisáveis por sua completude pragmática). Embora um único turno possa ser (e muitas vezes é) constituído por mais de uma unidade de construção de turno, ao final de cada uma dessas unidades, "a transição [de turno] para um outro falante se torna relevante (embora não necessariamente aconteça)" (1996:55). Quando a unidade vai se aproximando de um fim projetável, em que pode ser analisável como completa, tem-se um lugar relevante para a transição de turno, isto é, um lugar legítimo para que outro interlocutor possa tomar o turno, sem que isso configure interrupção.

7 Nas transcrições, à esquerda, "I" indica a iniciação de reparo, e "R" indica o resultado do reparo. 
iii) reparo iniciado pelo outro e levado a cabo pelo falante da fonte de problema (o interlocutor aponta um problema no turno anterior, e o próprio falante da fonte de problema resolve o problema no turno seguinte ao da iniciação);

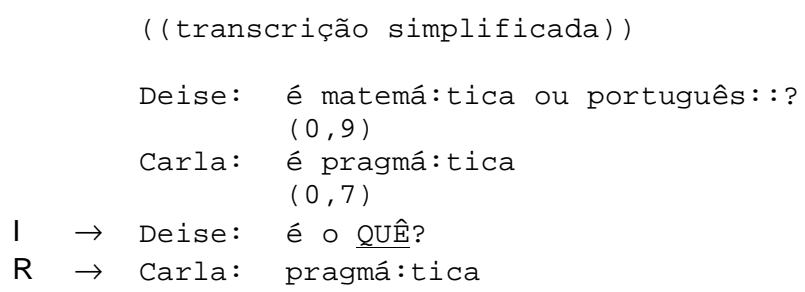

iv) e reparo iniciado e levado a cabo pelo outro - RILCO (o interlocutor aponta um problema no turno anterior e oferece resolução). ${ }^{8}$

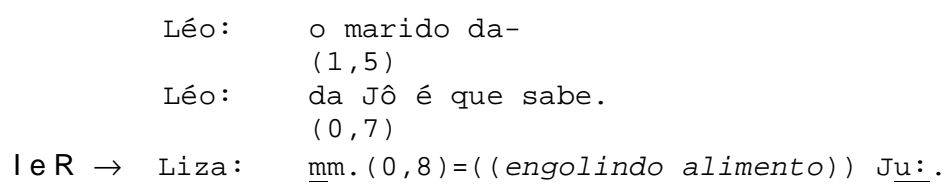

Cabe frisar que, quando um problema interacional é apontado por uma iniciação de reparo, lidar com o problema passa a ser a ação relevante a seguir, podendo tomar precedência a qualquer outra ação que possa ter sido tornada relevante a seguir e que, nesses casos, é suspensa para que o problema seja resolvido. Isto é, ao iniciar reparo, os interagentes podem apontar um impedimento para a produção do turno e/ou da ação em curso ou da ação relevante a seguir. Assim, interrompem o fluxo do que vinha sendo feito para apontar um problema e tentar remover o impedimento para que se possa prosseguir desde onde houve o problema. Essa capacidade de se sobrepor inclusive a uma ação tornada relevante a seguir parece ser privilégio da organização do reparo em relação à organização de outros fenômenos interacionais. Nas palavras de Schegloff (2000a:208), trata-se

\footnotetext{
8 Mais recentemente, outras trajetórias de reparo foram descritas, a saber, reparo em terceira posição e reparo em quarta posição (Schegloff 1991, 1992b; ver também Schegloff 1997b), que são de ocorrência rara também por razões seqüenciais. O estudo do reparo em terceira posição também vem sendo feito em interações em português brasileiro (Loder, Gonzalez \& Garcez 2004; Gonzalez 2004).
} 
do "único tipo de ação de que sabemos que tem essa propriedade [de poder se sobrepor a outras ações tornadas relevantes a seguir]" (grifo no original).

Crucialmente, no seu artigo seminal, Schegloff, Jefferson e Sacks (1977) constataram haver uma preferência ${ }^{9}$ pelo reparo levado a cabo pelo falante da fonte de problema (seqüências apresentadas em i e iii acima). Nos dados que observaram, essa foi a prática de maior recorrência. A maioria dos problemas apontados (tanto pelo falante quanto por seu interlocutor) é resolvida pelo próprio falante que produziu a fonte de problema. Isso está relacionado às técnicas de iniciação de reparo pelo próprio falante da fonte de problema e pelo outro interlocutor, que são diferentes. Por um lado, a grande maioria das técnicas de iniciação pelo falante da fonte de problema (no mesmo turno e no espaço de transição) permite a combinação das operações de apontar a fonte de problema e levar a cabo o reparo em um único componente. Assim, no excerto c que apresentamos acima, em dos surdos na::: $(0,4)$ no jogo, o item "no" aponta o problema de "na" e, ao mesmo tempo, é seu substituto. Nas técnicas de iniciação de reparo pelo outro interlocutor, por outro lado, as operações de localizar a fonte de problema e fornecer um reparo são separadas, feitas por componentes distintos, em turnos distintos (permitindo que um reparo seja iniciado pelo outro e depois levado a cabo pelo falante da fonte de problema, mantendo-se a preferência por auto-reparo). Além disso, note-se que quase todas as oportunidades de iniciação de reparo e resolução por parte do próprio falante vêm seqüencialmente antes das oportunidades para o outro interlocutor fazê-lo, o que explica o grande número de reparos iniciados e levados a cabo pelo falante da fonte de problema. Os autores mencionam, em alguns momentos, que parece haver, também, uma preferência pela iniciação de reparo pelo falante da fonte de problema em relação à iniciação pelo outro.

Observaram ainda que há uma despreferência pelo reparo levado a cabo pelo outro (seqüências apresentadas em ii e iv acima), uma vez que

\footnotetext{
9 A noção de preferência não está atrelada a questões de gosto pessoal, mas é, aqui, uma noção associada à recorrência de certo fenômeno e a questões seqüenciais observáveis, como hesitação e atraso (ver Pomerantz 1984). A oposição preferido/despreferido se assemelha à distinção não-marcado/marcado em Lingüística. Assim, um fenômeno preferido é de ocorrência recorrente e é produzido tipicamente sem hesitação nem atrasos. Um fenômeno despreferido é de ocorrência menos comum, apresenta hesitação e atraso (silêncios), e sua produção acarreta conseqüências interacionais com as quais os participantes têm que lidar para justificar a ação (isto é, questões de accountability, ver nota a seguir).
} 
esse é o reparo de ocorrência menos freqüente (sua oportunidade de ocorrência é precedida pelas oportunidades de reparo do próprio falante), e que pode vir marcado com atrasos (lapsos de tempo entre a fonte de problema e a iniciação do reparo, dando mais uma oportunidade para que o próprio falante repare seu próprio turno), com hesitações e modalizações (prefácios do tipo "you mean" / "I think" em inglês). Isto é, a ocorrência de reparo levado a cabo pelo outro pode vir ou não acompanhada desses itens: em vindo, é chamada de modalizada. Sobre a localização seqüencial, observaram que um grande número de reparos não-modalizados levados a cabo pelo outro ocorriam em seguida de um reparo modalizado ou de uma verificação de entendimento. Assim, observaram que a despreferência do reparo pelo outro vem marcada por sua modalização e/ou por sua posição seqüencial.

Quanto a esse último aspecto, é importante aqui mencionar que pode haver uma certa controvérsia a respeito do exato entendimento da diferença entre, de um lado, a correção de um entendimento candidato (o que os autores chamam de verificação de entendimento, checking understanding), caso em que, após um turno, o outro interlocutor interrompe o andamento para perguntar "você quer dizer X?" / "you mean X?", querendo confirmação sobre seu entendimento do que o outro está dizendo), e, de outro, o RILCO modalizado (em que um problema no turno do falante é reparado pelo outro interlocutor e o turno do reparo vem prefaciado com itens que marcam um certo grau de incerteza, muitas vezes, em inglês, o mesmo "you mean X?") (ver McHoul 1990:370-371). Apesar disso, nos parece que a distinção entre os dois fenômenos seja a seguinte: no primeiro caso, há correção do entendimento candidato que já era em si uma iniciação de reparo, não se configurando em RILCO, já que é o material do próprio corretor que continua em pauta como fonte de problema. No segundo caso, em que a fonte de problema é material produzido pelo corrigido, aí temos RILCO.

É útil retomar o raciocínio que se faz sobre as implicações seqüenciais do RILCO para se entender e apreciar como e por que se trata de um fenômeno de ocorrência rara em comparação às outras trajetórias de reparo. Ora, em primeiro lugar, tem-se que as trajetórias de auto-reparo são oportunizadas seqüencialmente antes da iniciação de reparo pelo outro e muito antes do reparo pelo outro, de modo que, toda vez que o produtor da fonte de problema lança mão dessas oportunidades de auto-reparo, 
esvazia-se a oportunidade de RILCO, o que explica em parte a sua raridade. Além disso, se as práticas de reparo pelo outro têm por finalidade remover problemas de escuta ou de entendimento para que a interação possa prosseguir, então, nos casos em que o interlocutor foi capaz de entender o que o falante disse a ponto de poder identificar que houve um problema, e ainda também indicar a solução (o reparo propriamente dito), não haveria um problema de entendimento de fato. Portanto, dificilmente se justifica ${ }^{10}$ que o reparo seja sequer iniciado, o que também explica a raridade de ocorrência do fenômeno. Segundo vários autores, quando é o caso de perceberem o problema e a sua solução, o que os interlocutores comumente podem fazer e de fato fazem é "deixar passar" qualquer que seja o problema no turno do outro, dando prosseguimento à interação, sem iniciar reparo. Além de realçar o caráter sistemático que enseja a raridade de ocorrência de reparo levado a cabo pelo outro, essas implicações seqüenciais explicam a existência da modalização nos reparos pelo outro de fato produzidos: quando o interlocutor não tem razões para duvidar de seu entendimento, ele dá prosseguimento à interação, "deixando passar" o problema do turno anterior (ver Firth 1996); do contrário, ele faz o reparo modalizado, que está sujeito à rejeição ou confirmação do falante da fonte de problema.

Contudo, os autores mencionam que, quando ocorre o reparo levado a cabo pelo outro, isso pode ser entendido pelos participantes como mais do que um mero reparo, mas como uma discordância. Conforme lembra Jefferson (1987:88), "[um interlocutor] corrigir [o outro] pode ser uma questão não meramente de pôr as coisas em ordem (...), mas de focalizar

\footnotetext{
10 Justamente aí temos a noção de accountability (prestação de contas), um dos conceitos mais centrais no pensamento etnometodológico (ver Coulon, 1995; Heritage, 1987/1999), segundo a qual a organização da ação social está pautada pela necessidade que os integrantes do grupo têm de agir de modo que suas ações sejam evidentemente justificáveis naquela juntura interacional segundo o possível julgamento dos pares que estivessem naquela mesma juntura. "As prestações de contas dos membros estão reflexivamente e essencialmente ligadas, por suas características racionais, às ocasiões socialmente organizadas de seu uso porque são características das ocasiões socialmente organizadas de seu uso" (Garfinkel 1967:4). Isto é, ao agir, estamos continuamente prestando contas da adequação de nossas ações à medida que construímos nossas ações. Não se trata de um evento extraordinário, mas de uma realização contínua ao longo de uma interação, sem que os interagentes tematizem a prestação de contas o tempo todo. É apenas em momentos em que essa contínua prestação de contas possa parecer sob suspeita (por exemplo, quando alguém produz uma fonte de problema interacional e é corrigido, trazendo à tona o lapso de competência do participante) que ela poderá se tornar parte do negócio interacional.
} 
especificamente lapsos de competência e/ou conduta". Essa observação abre a possibilidade de que o RILCO seja explorado pelos participantes não só como recurso para resolver problemas de entendimento, mas como um dispositivo (Drew, 1997) para realizar outras ações sociais dirigidas a coagir o outro ou a constranger a ação do outro, isto é, à tentativa de construir o próprio status informacional superior ao do outro, às vezes como método de imposição do direcionamento da conduta do outro, como no discurso da sala de aula tradicional (Batista 1997; Garcez no prelo).

Uma distinção lexicalmente sutil, mas interacionalmente importante, introduzida por Jefferson (1987) foi entre a ação de corrigir e a prática da correção, já que é possível implementar a ação de corrigir sem abrir uma seqüência em que a atividade interacional seja a correção (ou seja, sem iniciar reparo). Jefferson chama essas ocorrências de correção encaixada, em que a correção (oferta de substituição de um item por outro) é incorporada às ações já em andamento na interação, contrastando isso com o que chama de correção exposta, em que as ações em andamento são efetivamente suspensas, e corrigir torna-se a ação focal em que os interagentes estão engajados (constituindo, nesse caso, uma seqüência de reparo).

\section{Estudos sobre reparo levado a cabo pelo outro e sobre correção}

Talvez por sua escassa ocorrência e pela conseqüente dificuldade de reunir uma coleção considerável de ocorrências da trajetória de reparo levado a cabo pelo outro para estudo, até hoje há poucos estudos que examinam especificamente esse fenômeno no âmbito da literatura internacional. Centrados na correção feita pelo outro, temos notícia dos trabalhos de Norrick (1991) e de Kurhila (2001), além do trabalho de Jefferson (1987), mencionado acima. ${ }^{11}$ Assim, a descrição em Schegloff, Jefferson e Sacks (1977) permanece sendo a mais importante.

11 Norrick (1991) elabora um entendimento diferente de certas características do fenômeno, considera as identidades dos participantes a priori (posição discrepante com a ACE) e analisa alguns excertos de interações pai/criança, professor/aluno e nativo/não-nativo, chegando à conclusão de que "a correção normalmente serve para equilibrar quaisquer diferenças no conhecimento prévio e, assim, amplia o entendimento, a interação e o progresso em direção ao objetivo comum” (1991:80). Kurhila (2001), por sua vez, discute a recorrência de correções pelo outro em interações entre falantes nativos e falantes não-nativos quando a fonte de problema inclui problemas de ordem 
Contudo, suas observações tinham como objeto de análise ocorrências de reparo levado a cabo pelo outro (englobando, assim, ocorrências de reparo iniciado pelo outro ou pelo falante da fonte de problema). No presente estudo, entretanto, nosso objeto de análise é um tipo específico de reparo levado a cabo pelo outro, o reparo iniciado e levado a cabo pelo outro, uma trajetória específica, em que iniciação e resultado são feitas pelo mesmo outro, o interlocutor do participante que proferiu o turno com a fonte de problema. Assim, enfocamos uma trajetória que, dentro do sistema de reparo, é a mais despreferida, por apresentar a particularidade de realizar iniciação e resolução pelo mesmo interagente, sendo, por isso, de ocorrência ainda mais rara.

Cabe registrar que, no Brasil, há estudos publicados que lidam explicitamente com a questão da correção (por exemplo, Barros 1993; Fávero 1997; Fávero, Andrade e Aquino 1999; Fávero 1997). Barros (1993) centra sua análise em um inquérito do Projeto NURC/SP e investiga a recorrência do fenômeno que denomina correção (definido como um ato de reformulação textual, que tem semelhanças com o fenômeno da paráfrase) e discute ocorrências de correção feitas pelo próprio falante da fonte de problema (o que chama de autocorreção) e pelo outro interlocutor (o que chama de heterocorreção). Fundamentalmente, a correção é entendida aí como um procedimento que visa a solucionar problemas para "garantir a intercompreensão na conversação” (1993:139). Ao tratar de classificação, tipos de erro, marcadores lingüísticos e funções da correção, a análise registra que foi encontrado número bem menor de heterocorreções do que de autocorreções, sustenta que a correção é um procedimento importante na organização da conversa e argumenta que as relações entre os interlocutores dependem da presença e do tipo de correção empregada (1993:154).

Fávero, Andrade e Aquino (1999) analisam nove inquéritos do Projeto NURC e algumas "conversas espontâneas" para investigar três tipos de correção (assim chamadas autocorreções auto-iniciadas, autocorreções hetero-iniciadas e heterocorreções auto-iniciadas) quanto a sua tipologia, operacionalização, marcas prosódicas e lingüísticas, e funções. O texto con-

gramatical e conclui que, em seus dados (falantes nativos e não-nativos de finlandês), nem todos os problemas gramaticais eram corrigidos pelo falante nativo, havendo alguns ambientes seqüenciais que propiciam a correção encaixada e outros a correção exposta, sendo essa também observação de Firth (1996), que analisou interações telefônicas entre falantes de diversas línguas maternas que interagem em inglês. 
clui que a correção é um dos mecanismos mais utilizados na fala (tanto nos inquéritos quanto nas conversas espontâneas analisadas) e que "correspondem a um processo altamente interativo e colaborativo” (1999:74).

Por fim, Fávero (1997) discute centralmente a ocorrência de autocorreções auto-iniciadas (caracterizadas como processo de formulação retrospectivo) e de hesitações (caracterizado como processo de formulação prospectivo) em elocuções formais de inquéritos no Projeto NURC/SP. Além de apontar também uma dificuldade em distinguir entre paráfrase e correção, o estudo apresenta as características, a operacionalização, os tipos e as funções de cada um desses fenômenos.

Observamos que nenhum desses estudos sobre correção em português brasileiro trata focalmente de interações cotidianas de ocorrência natural (entendidas como a forma de socialização fundadora, conforme discutido acima), já que se valem, em sua maior parte, de dados de entrevistas sociolingüísticas. Além disso, notamos que, apesar de focar o fenômeno da correção (seja pelo outro interlocutor, seja pelo falante da fonte de problema), não se pautam pela organização seqüencial sistemática das ocorrências, de modo que práticas de correção (substituição de um item considerado errado por outro considerado certo) são o foco, a despeito de haver iniciação de reparo ou não. Sobretudo, não há ali uma discussão específica sobre a ação de corrigir mediante reparo iniciado e levado a cabo pelo outro. Assim, circunscrevemos nosso objeto de análise a esse tipo específico de reparo e trazemos a contribuição da análise de ocorrências naturais em dados de fala-em-interação em português brasileiro (diferente de entrevistas préestruturadas ou com a presença do documentador) para o cenário do debate dessas questões no Brasil. Nosso interesse foi investigar se (e como) os interlocutores se orientam para a despreferência do RILCO e verificar quais elementos estruturais seqüenciais estão envolvidas nessa trajetória de reparo.

\section{Dados de análise}

Nosso material de análise constitui-se de cerca de 15 horas de registros em áudio e/ou vídeo de interações cotidianas, de ocorrência natural, em diferentes cenários: mesa de jantar em família, mesa de bar em faculdade, conversas ao telefone. A geração desses dados foi feita ao longo de alguns anos por pesquisadores do Grupo de Pesquisa "Interação Social e 
Etnografia" e por alunos de graduação e pós-graduação que, após cursarem disciplinas em que eram solicitados a fazer gravações e transcrições nos moldes da ACE para análise e discussão, doaram suas contribuições ao acervo do Grupo. Para todos os registros, tem-se o consentimento dos participantes, registrado na própria gravação ou fornecido diretamente ao pesquisador no momento da gravação. Os dados que se apresentam foram transcritos conforme o sistema desenvolvido por Gail Jefferson (Atkinson \& Heritage 1984; ver anexo abaixo). Os participantes são identificados por pseudônimos (ver Garcez 2002a).

Nesse universo de 15 horas de registros de fala-em-interação cotidiana em português brasileiro, identificamos $28^{12}$ ocorrências de RILCO. Desse total, selecionamos algumas ocorrências para a presente discussão do fenômeno.

\section{Preferência e reparo iniciado e levado a cabo pelo outro na conversa cotidiana em português brasileiro}

O primeiro excerto que discutiremos faz parte de uma conversa telefônica entre as amigas Cris e Lu. ${ }^{13}$ Elas estão organizando uma festa e, entre outras coisas, discutem a compra de bebidas. Gostariam de comprar chope, mas, após pesquisas de preço junto a distribuidores, chegam à conclusão de que comprar cerveja seria mais econômico:

\footnotetext{
12 Desse total, há três ocorrências de interação entre adulto e criança com propósitos de tratamento de tarefa escolar (assemelhando-se à interação institucional de sala de aula).

13 Dados de uma outra conversa telefônica entre essas mesmas participantes no mesmo dia, tratando dos mesmo tópicos, são objeto de análise detalhada apresentada em Dornelles e Garcez (2001).
} 
Garcez \& Loder: Reparo Iniciado e Levado a Cabo pelo Outro...

\section{Excerto 1}

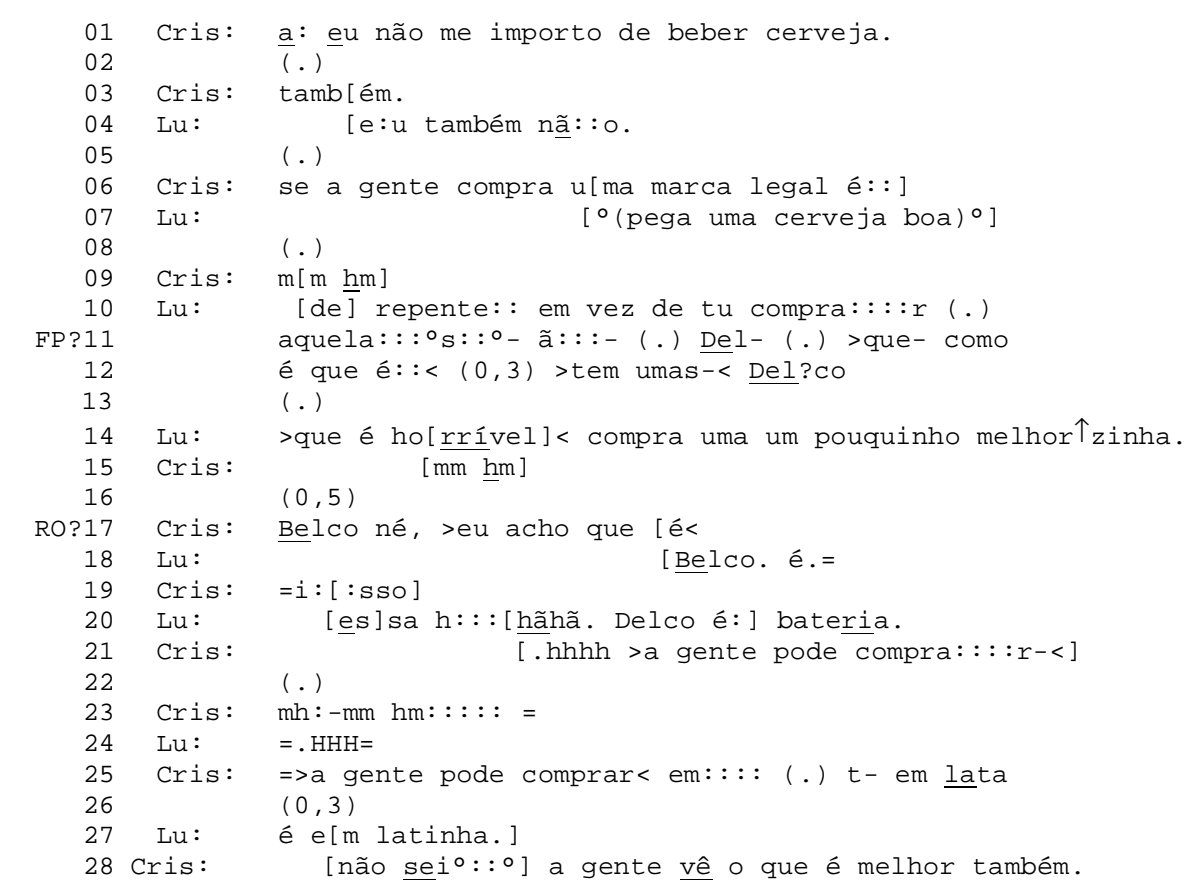

No turno das linhas 10-12, Lu menciona uma marca de cerveja (Delco, na primeira flecha, que será a fonte de problema - FP). No turno da linha 17, esse item vai ser corrigido por Cris (Belco, na segunda flecha, o reparo propriamente dito - R). Já nas linhas 10-12, Lu inicia reparo sobre seu próprio turno, interrompendo sua produção para procurar uma palavra (word search), o que fica evidente pelos prolongamentos de sons, cortes abruptos e atrasos. Nessa iniciação de reparo feita pelo falante da fonte de problema $(\mathrm{Lu})$, o outro interlocutor (Cris) poderia ter intervindo, para oferecer algum candidato para a busca de Lu. Contudo, Cris não intervém; Lu, ao final, encontra um candidato (Delco, linha 12), e, depois da micropausa (linha 13), retoma a construção de seu turno anterior (linha 14), concluindo sua sugestão de que comprem uma cerveja de boa procedência. Observe-se, portanto, que a seqüência de reparo iniciada por Lu na linha 10 se encerra, na linha 12, com a solução encontrada pela própria Lu (Delco). Tanto é assim que, na linha 14, Lu retoma a construção do turno suspensa enquanto se resolvia o problema. Além disso, na linha 15, quando havia oportunidade para iniciar reparo pelo outro, Cris, em sobreposição com o 
turno da linha $14 \mathrm{de} \mathrm{Lu}$, profere um continuador, $m m \underline{\mathrm{h}} m$, sinalizando que está acompanhando Lu e, quem sabe, concordando com a sugestão de que comprem cerveja de certas marcas e não de outras. Apenas após Lu ter, finalmente, completado seu turno, e após um atraso de cinco décimos de segundo (linha 16), conferindo ainda mais uma oportunidade a Lu para que faça auto-reparo, Cris abre nova seqüência de reparo, realizando o RILCO ao dizer Belco né, >eu acho que é<, propondo assim Belco como substituto para Delco, proferido por Lu na linha 12. Note-se, ainda, que o reparo aqui vem no formato modalizado, isto é, o item proposto como substituto vem acompanhado de né e de $>e$ acho que é< (linha 17), associando ao reparo certo grau de incerteza, sinalizando o caráter despreferido da ação que se implementa nesse turno.

Portanto, a preferência pelo auto-reparo está aqui marcada pelas oportunidades desprezadas para fazer auto-reparo que Lu teve antes de Cris se manifestar (linhas 13 e 16), e a despreferência ${ }^{14}$ do RILCO, pelas modalizações no turno que faz o reparo e pelos atrasos de Cris para iniciá-lo (concordância na linha 15 e silêncio entre turnos na linha 16).

Especificamente quanto a preferência, observamos, em nossa coleção, não só ocorrências em que a iniciação e o resultado do reparo pelo outro são levados a cabo no mesmo turno (como a que foi apresentada acima), mas também ocorrências em que a iniciação pelo outro é feita em um turno, e o resultado pelo outro é levado a cabo em um turno distinto, como a seguir:

14 Em nossa argumentação, recorrentemente fazemos recurso ao que chamamos de marcas de despreferência. Contudo, cabe esclarecer que a identificação e conseqüente análise das mesmas está, antes de tudo, centrada no desenvolvimento da sequiência interacional em si, da qual essas marcas fazem parte. Dito de outro modo: os elementos que constituem as marcas não são considerados, para os propósitos da ACE, como elementos a priori, que, uma vez identificados em qualquer seqüência, tenham valor de símbolo de despreferência. Crucialmente, a análise passa por identificar onde tais elementos se encontram na seqüência interacional, o que os participantes estão fazendo com eles para que, daí então, sejam analisados como marcas de despreferência. Nesse sentido, no excerto 1, apresentado acima, a micropausa na linha 05 não necessariamente é índice de despreferência da ação que Cris fará na linha 06. Por outro lado, dado que Lu iniciou seu turno da linha 04 em sobreposição com o final do turno da linha 03 de Cris, ela (Cris) talvez esteja esperando que Lu prossiga seu turno, fazendo algum comentário mais substancial de apoio à iniciativa de Cris de trocar o chope pela cerveja. Como Lu não dá continuidade a seu turno, nem toma a palavra novamente, Cris, após a micropausa, inicia novo turno e encaminha proposta de procedimento para comprarem as bebidas para a festa (linha 06, se a gente compra uma marca legal). Assim, fica evidente a importância crucial da análise situada, de cada interação, a fim de observar como os participantes 


\section{Excerto 2}

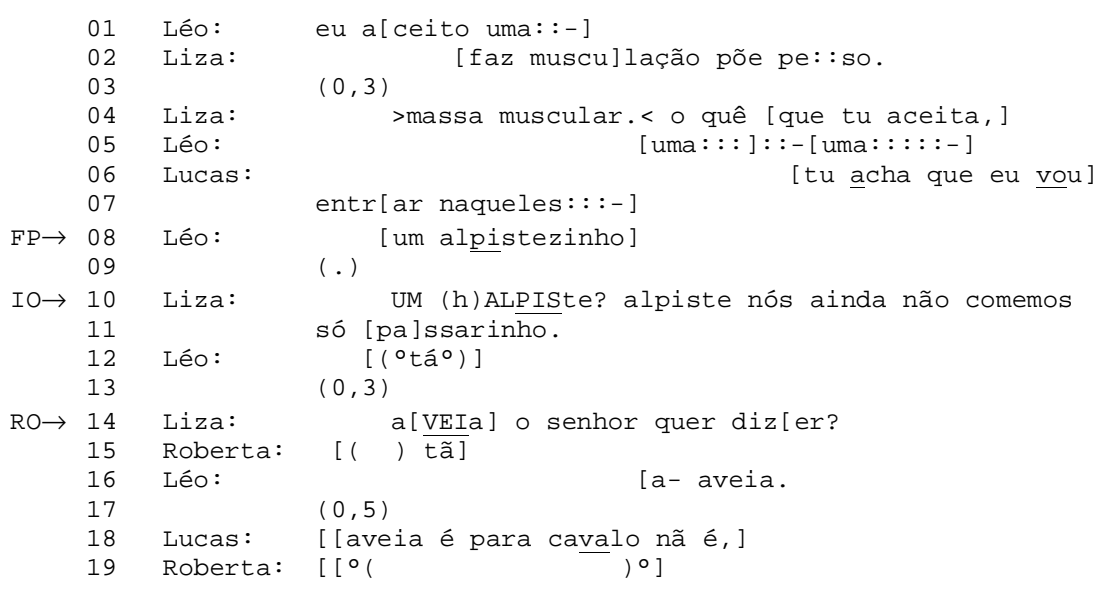

O fragmento acima faz parte de uma interação em torno da mesa de jantar em família. Imediatamente antes do que se apresenta no segmento reproduzido acima, Liza e Lucas estavam discutindo sobre o porte físico de Lucas, e Liza sugere a Lucas que faça musculação para ganhar peso (linha 02). Pouco antes de Liza começar seu turno, porém, Léo inicia a construção de um turno com um novo tópico (provavelmente uma solicitação para que lhe alcancem algo na mesa), dizendo, no turno da linha 01, eu atceito uma::-. No turno da linha 04, Liza, na primeira parte, parece ainda estar lidando com Lucas quando diz $>$ massa muscular. $<{ }^{15}$ e, em seguida, se orienta para a solicitação de Léo, dizendo o quê que tu aceita. Enquanto Léo prossegue na construção de seu turno para completar sua solicitação (linha 05), Lucas parece ainda estar orientado para o tópico anterior, respondendo à sugestão de Liza de que ele fizesse musculação ( $t u$ acha que eu vou entrar naqueles::.: - linhas 06 e 07). Em sobreposição com o final do turno de Lucas (que será abortado antes de chegar ao fim), Léo completa a solicitação iniciada no turno da linha 01, dizendo um alpistezinho (linha 08). Após uma micropausa (linha 09), Liza toma o turno e aponta uma fonte de

estão tornando certas "marcas" relevantes para a ação que está em jogo. E, como em ACE nos interessa aproximar a perspectiva dos participantes da interação, é a análise indicial caso a caso dos métodos sociais recorrentes o que vai nos interessar, e não símbolos genéricos de despreferência descontextualizados da seqüência interacional. Daí a descrença com relação à possibilidade de se estabelecer relações biunívocas entre forma e função estáveis a despeito dos contextos seqüenciais. 15 Aqui, Liza faz um auto-reparo sobre seu próprio turno anterior, propondo a substituição de peso por massa muscular. 
problema no turno anterior de Léo. Ela diz, com ênfase de volume, $U M$ (b) ALPISte? alpiste nós ainda não comemos só (pa)ssarinho. Segue-se, depois do assentimento de Léo (linha 12) de que há, de fato, um problema em seu turno anterior, um silêncio de três décimos de segundo (linha 13), configurando-se como uma oportunidade para Léo tomar a palavra e levar a cabo o reparo sobre seu próprio turno. Uma vez que Léo não toma essa oportunidade, Liza apresenta um candidato para substituir a fonte de problema alpistezinho da linha 08; ela diz aVEIa o senhor quer dizer? (linha 14). Aqui se trata de um reparo levado a cabo pelo outro com modalização ( $X$ o senhor quer dizer?). Assim, as marcas de despreferência pelo RILCO, nesse segmento ficam patentes pelo atraso de Liza em iniciar o reparo, pela oportunidade não aproveitada de Léo em levar a cabo o reparo sobre sua própria fonte de problema e pelo uso da modalização.

Em ambos os excertos, temos ocorrências em que é o interlocutor (isto é, o outro) quem aponta o problema e provê uma alternativa (seja realizando essas duas ações em um só turno ou em dois turnos distintos), e, em ambos os casos, as marcas de despreferência por RILCO ficam evidentes (seja pelos atrasos em iniciar ou levar a cabo o RILCO, seja pelas modalizações).

Em nossa coleção do fenômeno, a grande maioria das ocorrências (26), assim como as que estão reproduzidas acima, apresenta claras marcas de despreferência pelo RILCO (seja por atrasos, seja por modalização, ou ambos), em consonância com as observações feitas sobre interações em inglês norte-americano. Contudo, é relevante observar que apenas quatro dessas 26 ocorrências apresentaram modalização (sendo que duas são as apresentadas acima), e, em todas elas, ocorreu atraso também. Nas demais ocorrências, há apenas atraso, o índice de despreferência mais comum no nosso corpus.

Ainda, é importante ressaltar que, embora os excertos apresentados acima contenham atrasos na forma de silêncios entre o turno da fonte de problema e o de início de reparo pelo outro, o atraso pode se configurar também quando o interlocutor aguarda que o turno que contém a fonte de problema atinja um lugar relevante para a transição de turno. ${ }^{16} \mathrm{O}$ excerto a seguir é exemplar.

Roberta começou a contar uma notícia, e Liza entra em co-autoria, ao retificar uma informação dada por Roberta:

16 Ver nota 5 acima para discussão da noção de lugar relevante para a transição de turnos. 


\section{Excerto 3}

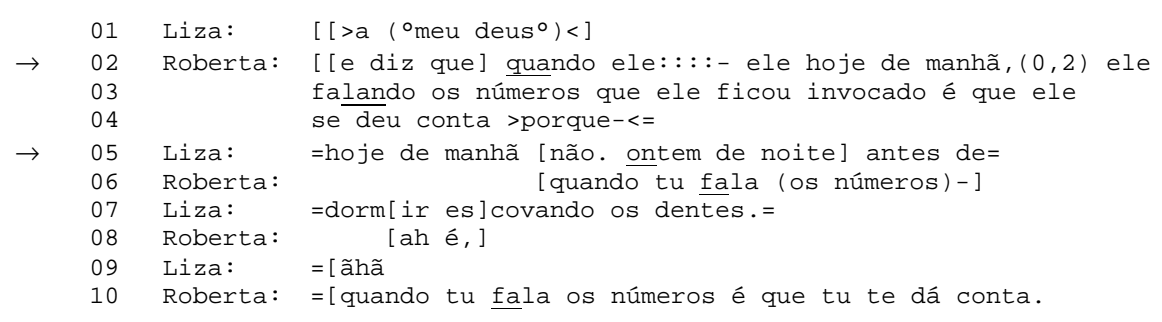

No turno da linha 02, Roberta informa que o evento narrado se passou hoje de manhã, informação que será reparada por Liza no turno das linhas 05 e 07 a seguir, quando ela diz hoje de manbã não. ontem de noite antes de dormir escovando os dentes. Entretanto, a produção da fonte de problema se dá no meio de uma unidade de construção de turno de Roberta. Liza, que poderia já ter tomado a palavra para fazer o RILCO em seguida da produção de hoje de manhã (linha 02), aguarda até que o turno de Roberta atinja um ponto relevante de transição para tomar a palavra e fazer o RILCO. Observa-se que Liza entra em um ponto legítimo, relevante para a transição, uma vez que a produção "e diz que quando ele::::- ele boje de manhã, ele falando os números que ele ficou invocado é que ele se deu conta" tem completude sintática e, por isso, seria uma unidade de construção de turno completa, sendo que o restante do turno de Roberta $(>$ porque $-<$ ) introduz uma segunda unidade de construção de turno (abortada antes de ser completamente produzida). Assim, observa-se que Liza só produz RILCO depois de um atraso (que aqui não se configura como silêncio, mas em Liza conter-se até que a unidade de construção de turno de Roberta atinja um ponto de transição possível), e, nesse caso, sem modalização.

Quanto à modalização nos turnos de reparo levado a cabo pelo outro, Schegloff, Jefferson e Sacks (1977:378) mencionam que, uma das formas mais comuns de modalização em inglês é o uso do prefácio You mean $X$ ? (você quer dizer $X$ ?). Entretanto, em nossa coleção de ocorrências, observamos apenas uma vez o uso de uma expressão semelhante: o senhor quer dizer? (linha 14 do excerto 2 acima). As demais expressões de modalização observadas em três outras ocorrências foram né e eu acho que é. Essa diferença entre as expressões usadas na modalização em inglês e em português não põe em xeque nossa constatação afirmada em parágrafo anterior, de que as observações sobre as ocorrências de RILCO em português se assemelham às em inglês. Porque o uso de uma determinada expressão está 
mais diretamente relacionado às especificidades de cada língua, trata-se de uma questão variável de língua para língua. O que é central para a discussão da organização do sistema de reparo é a orientação dos participantes para a despreferência por RILCO, e esse aspecto, para além das particularidades lingüísticas do português brasileiro e do inglês norte-americano, fica empiricamente evidente nos dados, confirmando que a descrição do fenômeno de RILCO feita sobre dados em inglês norte-americano tem validade também para as interações em português brasileiro.

\section{Composição dos turnos}

A composição dos turnos envolvidos no RILCO, tal como os observamos, difere um pouco da descrição que Schegloff, Jefferson e Sacks (1977) fazem acerca do reparo pelo outro em geral. Conforme relatamos acima, essa descrição mencionava que, enquanto na grande maioria das iniciações de reparo pelo falante da fonte de problema, as operações de apontar e resolver o problema eram feitas ao mesmo tempo por um só componente, nos reparos iniciados pelo outro, essas operações eram realizadas por componentes separados.

O que observamos em nossa coleção é que há, de fato, ocorrências em que, mesmo o outro interlocutor produzindo iniciação e resolução de reparo no mesmo turno, se observa claramente o emprego de dois componentes diferentes para a realização das operações de iniciação e resolução, como no excerto 3 (repetido abaixo):

\section{Excerto 3}

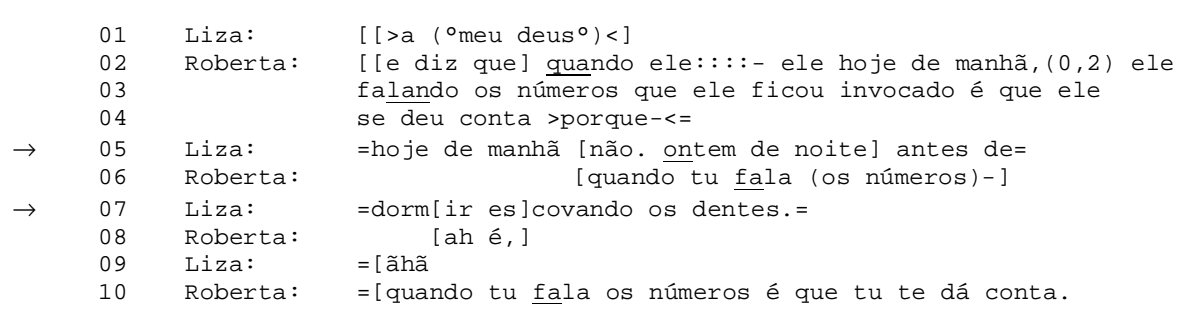

O turno da linha 05 de Liza apresenta o segmento hoje de manhã não, que aponta o problema presente no turno anterior da interlocutora (isto é, inicia reparo), e o segmento ontem de noite antes de dormir escovando os dentes, 
que se configura como o candidato a substituir a fonte de problema apontada (isto é, o resultado do reparo).

Entretanto, também temos ocorrências como a seguinte, na ligação telefônica entre Patrícia e Paulo (que foi quem ligou). Nesse momento, Paulo está ditando a Patrícia o seu número de telefone:

\section{Excerto 4}

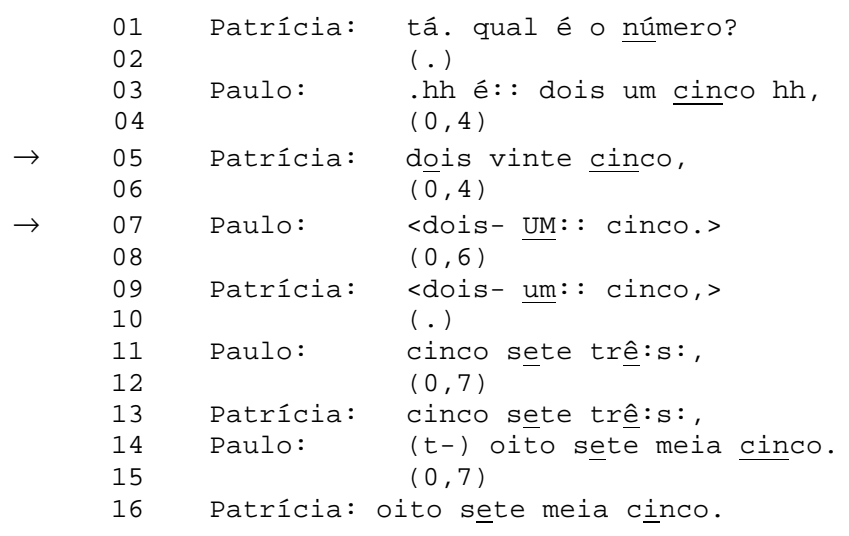

Aqui, ao fazer a correção $<$ dois- $\underline{U M}:$ : cinco $>$, a ênfase no segundo dígito da seqüência (um) sinaliza, ao mesmo tempo, onde está o problema no turno anterior (no segundo dígito do turno 05 de Paula, vinte) e oferece o seu substituto (um). Ou seja, o item um inicia e, ao mesmo tempo, leva a cabo o reparo pelo outro.

Em resumo, diferentemente do registrado na literatura quanto ao reparo pelo outro, observamos, em nossa coleção, instâncias em que um único componente realiza o trabalho de apontar e resolver o problema de uma só vez.

\section{Sinalizações e recibos}

Nos excertos apresentados até agora, centramos nossa análise e nossas discussões principalmente em dois turnos: o turno que traz a fonte de problema e o turno seguinte, em que o reparo é iniciado e levado a cabo pelo outro. Entretanto, retomando a citação de Jefferson (1987) (reproduzida 
na seção "Noções fundadoras" acima), fica claro que a correção (e, no nosso caso, de modo mais estrito, o RILCO), além de esclarecer equívocos, pode estar também sendo usada pelos participantes para realizar uma outra ação: apontar lapsos na produção do outro interlocutor, destacando o erro como parte relevante do negócio interacional. Isso nos levou a analisar o que acontece na seqüência interacional depois que o RILCO é feito a fim de observar o que o participante reparado faz nessa circunstância em que um lapso seu está sendo exposto, isto é, como ele lida com essa exposição.

Inicialmente, verificou-se que, após o turno de reparo, na grande maioria dos casos (em 21 das 28 ocorrências de nossa coleção), quem ocupa o turno seguinte é o interlocutor reparado (no primeiro excerto reproduzido acima, é Lu quem toma o turno seguinte ao RILCO, linha 18; no segundo excerto, é Léo, linha 16; e no terceiro excerto, Roberta, linha 8). Nesses turnos seguintes, observou-se que a ação em que se engaja o interlocutor reparado é dar alguma sinalização de que foi corrigido, de que se sentiu reparado, consentindo com o reparo feito sobre seu turno anterior.

Foram duas as práticas observadas na construção desse terceiro turno da seqüência de RILCO. A primeira foi de dar um recibo do reparo, repetindo o item corrigido, sozinho ou incorporado a uma repetição (parcial ou total) do turno da fonte de problema. Conforme lembra Schegloff (1997a:527), "repetições [podem ser] usadas como reconhecimentos de recebimento", em que a repetição registra o recebimento "tanto do turno precedente quanto das ações levadas a cabo" no turno precedente.

O segmento a seguir ilustra esse caso. Léo e Liza estão na mesa de jantar em casa e estão relembrando anedotas e charadas. Então, Léo fala:

\section{Excerto 5}

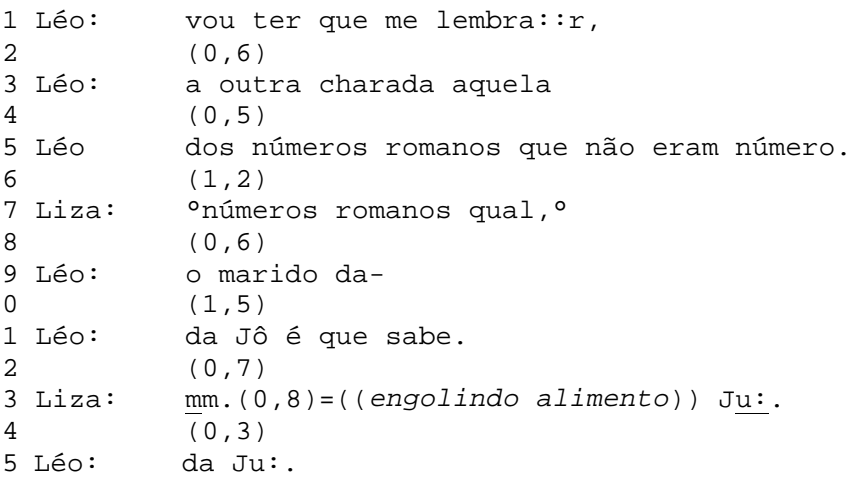


Nessa seqüência, o turno de Léo (linha 11) torna-se a fonte de problema (da Jô é que sabe), que, após um atraso de sete décimos de segundo (linha 12), é corrigido por Liza (linha 13 - com $\mathrm{mm}$, ela toma o turno, sinalizando que tem algo a dizer, e, após oito décimos de segundo em que engole o alimento, produz o reparo $J u$ ). Na seqüência (linha 15), Léo toma o turno e passa recibo do reparo de Liza sobre seu turno anterior. Esse recibo vem na forma de uma repetição parcial da fonte de problema com a incorporação do item corrigido; ele diz da Ju em vez de simplesmente $J u$ (que se configuraria como recibo com repetição apenas do item corrigido) ou $o$ marido da Ju é que sabe (que se configuraria como recibo com repetição de todo o turno problemático com a incorporação do item reparado). ${ }^{17}$

Observe-se que, entre o turno de RILCO e o de recibo, há um silêncio de três décimos de segundo, em que Liza não toma o turno. O silêncio apenas cessa quando Léo toma a palavra para lidar com o reparo, isto é, para lidar com um lapso seu que foi exposto pela sua interlocutora. Assim, há uma orientação dos participantes para o fato de que é o interlocutor corrigido quem deve tomar o turno depois do RILCO (enquanto ele não toma a palavra para lidar com o reparo do outro feito sobre o seu turno, o produtor do reparo também não toma a palavra).

Nesse caso, o recibo foi feito com a repetição parcial do turno problemático. Além desse formato, os recibos de reparo mais recorrentes em nossa coleção de ocorrências foram a repetição apenas do item corrigido (como na linha 16 do excerto 2 acima) ou a repetição/reelaboração de todo o turno problemático com a incorporação do item corrigido.

Além da prática de dar recibo, observamos também algumas ocorrências em que, no turno seguinte ao do reparo, o interlocutor reparado tomou o turno sinalizando, de maneira mais geral, o reconhecimento do reparo. Essa segunda prática se apresentou de diversas maneiras, seja com índices de mudança de status informacional (change-of-state token) (Heritage 1984), com justificativas/prestações de conta (accountability) para a produção da fonte de problema ou com topicalização e reelaboração da fonte de problema.

17 Sobre a dispensabilidade de elementos originalmente proferidos em repetições, ver Schegloff (2003). 
Abaixo, apresentamos uma ocorrência de ilustração (já apresentada na seção "Composição dos turnos", repetida aqui para comodidade do leitor):

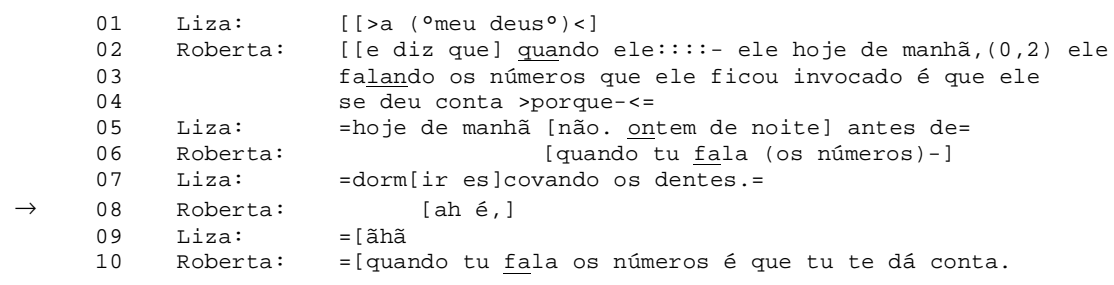

No turno da linha 08, Roberta profere um ah é, em sobreposição com o final do turno de RILCO (o que não a impede de ouvir e registrar ação de reparar desempenhada por Liza, dado que a elocução ontem de noite antes de dormir já poderia ser um substituto suficiente para a fonte de problema hoje de manhã). A entonação nesse turno da linha 08 de Roberta é ascentente (sinalizada com a vírgula final), indicando uma troca de status informacional que se caracteriza como uma prestação de contas que poderia ser glosada como "essa informação é nova para mim, eu não sabia que as coisas tinham sido assim", de modo que Roberta sinaliza o reconhecimento de que teve seu turno anterior reparado.

Nessa ocorrência, o turno de prestação de contas se inicia em sobreposição com o final do turno de RILCO. Ao contrário da ocorrência anterior, em que há um atraso após o reparo, aqui o interlocutor reparado aproveita a primeira oportunidade que se apresenta para lidar com a exposição de seu lapso (o final projetável da unidade de construção de turno ontem de noite antes de dormir).

Assim, a observação da seqüência que se segue após o turno de RILCO evidenciou que: a) na grande maioria das ocorrências (21), é o interlocutor reparado quem toma o turno seguinte ao RILCO; e que b) a ocorrência do RILCO parece tornar relevante que, no turno seguinte, o interlocutor reparado tome a palavra para lidar de alguma maneira com o fato de que um lapso em sua competência/conduta foi exposto. A orientação dos participantes para esse constrangimento interacional fica evidente na observação dos atrasos e sobreposições entre o turno de RILCO e o turno seguinte: se o participante reparado não lida imediatamente com a correção, há um atraso, e as ações seguintes ficam suspensas até que ele produza um turno que lide com o RILCO (como na primeira ocorrência analisada nesta seção). Por outro lado, se o participante corrigido toma o turno em sobrepo- 
sição com o final do turno de RILCO (como na segunda ocorrência analisada nesta seção), isso sinaliza que ele está aproveitando a primeira oportunidade interacionalmente disponível para lidar com a exposição de seu lapso.

Essas observações das seqüências que se seguem ao turno de reparo indicam que é relevante, na organização das trajetórias de RILCO, a orientação dos participantes para o trabalho extra que a ocorrência de RILCO cria para o interlocutor corrigido, nomeadamente, de ter que lidar interacionalmente com a exposição de seu lapso (seja através do recibo, seja através da sinalização mais geral). Assim, esse constrangimento interacional que o RILCO acarreta é mais uma evidência, a ser acrescentada às já exploradas pela literatura, de que se trata de uma ação despreferida.

Cabe frisar que o fato de que uma ação seja despreferida não significa que é proibida aos participantes; significa que, uma vez realizada, necessariamente implicará conseqüências interacionais com as quais os participantes terão que lidar (e, por isso, se diz que são práticas custosas em ações interacionalmente delicadas). No caso do RILCO, sendo essa uma ação despreferida, uma conseqüência adicional é o constrangimento para que o participante reparado se explique de alguma maneira (e, aqui, a delicadeza é ainda maior, porque não é o participante reparador quem tem que se explicar; essa responsabilidade recai sobre o próprio reparado).

\section{Reparo iniciado e levado a cabo pelo outro e discordância}

Uma última observação diz respeito à aproximação do fenômeno RIL$\mathrm{CO}$ com um outro fenômeno interacional (a discordância), já apontada em trabalhos anteriores. Conforme já mencionamos (seção "Noções fundadoras"), Schegloff, Jefferson e Sacks (1977:380) já haviam notado que, às vezes, o reparo pelo outro pode ser entendido pelos participantes como envolvendo mais do que simplesmente reparo, mas discordância. Embora não apresentem análise de dados para sustentar esse ponto, os autores fazem referência a tal possibilidade. Alguns anos mais tarde, M. H. Goodwin (1983:657), em seus estudos sobre interações entre crianças negras norte-americanas, registrou que corrigir e discordar são duas atividades relacionadas. Tendo como foco a comparação entre ações agravadas (explícitas) e mitigadas nas interações entre adultos e entre crianças, Goodwin timidamente ensaiou uma distinção entre essas duas ações: corrigir diria 
respeito a um elemento específico no turno anterior e discordar diria respeito à ação do turno anterior como um todo.

Embora, na análise de ocorrências, não seja imediata e objetiva a distinção entre seqüências de discordância e de RILCO, ao compor a coleção de ocorrências de RILCO que analisamos no presente trabalho, acabamos por reunir, também, uma coleção paralela de ocorrências que estão na fronteira entre esses dois fenômenos. Em outras palavras, mesmo não buscando inicialmente tratar do fenômeno da discordância, acabamos por identificar que, nas interações em português brasileiro, há também casoslimite, em que é difícil distinguir entre as ações de corrigir e discordar, ${ }^{18}$ em consonância com o que já estava também observado na literatura para dados em inglês norte-americano.

\section{Considerações finais e conclusão}

Conforme mencionamos na introdução deste trabalho, nosso interesse principal era averiguar se a descrição do RILCO em interações cotidianas tal como sugerida na literatura para interações em inglês norte-americano também seria válida para descrever RILCO em interações em português brasileiro. Acreditamos ter conseguido mostrar que, a partir das observações de nosso corpus de cerca de 15 horas de interações cotidianas em português brasileiro, a ocorrência de RILCO é também rara (foram encontrados apenas 28 segmentos) e despreferida, isto é, há orientação dos participantes para o fato de que corrigir o outro é uma ação delicada. Como evidências da despreferência por RILCO, identificamos a ocorrência de atrasos antes da iniciação de reparo pelo outro (seja na forma de silêncios ou não, conforme discutido acima) e, em alguns casos, de RILCO modalizado, sendo que algo semelhante à forma de modalização descrita como comum em inglês norte-americano (you mean $X$ ?) foi encontrada apenas em uma ocorrência em nossos dados. Assim, o índice de despreferência mais comum nos RILCOs de nosso corpus foi mesmo o atraso.

Entretanto, o fato de que encontramos pouca modalização lexical em nossas ocorrências não significa que a organização de RILCO em portu-

18 A análise detalhada dessas seqüências interacionais se encontra em andamento e uma discussão aprofundada sobre a distinção entre esses dois fenômenos aguarda publicação futura. 
guês brasileiro seja substancialmente diferente daquela descrita para interações em inglês, sobretudo porque não encontramos qualquer distinção seqüencial digna de nota. Fica claro que, nas interações em ambas as línguas, observa-se sistematicamente orientação dos participantes para a despreferência por RILCO, embora os participantes de interações indiciem essa orientação com expressões ou recursos que são particulares a cada língua. Assim, adaptando a citação de Schegloff (2000a:241), mencionada na introdução deste trabalho, observou-se, em nossa coleção, que a organização do reparo parece, até agora, ser estável através dos limites lingüísticos e culturais e, ao mesmo tempo, adaptável a suas especificidades, sendo as diferenças observadas no que tange à modalização um exemplo da especificidade lingüística em operação nas ocorrências de RILCO.

Além dessa observação geral, nossas análises acerca da organização de RILCO nos permitiram também apontar aspectos ainda não explorados na literatura, que acreditamos ser contribuições relevantes para um aprofundamento na compreensão desse fenômeno e do sistema de reparo como um todo. Especificamente, em primeiro lugar, observamos que, no que diz respeito à composição dos turnos que realizam o RILCO, as ações de iniciar e levar a cabo o reparo pelo outro podem não só ser empreendidas por componentes distintos, tal como já previsto e apontado em Schegloff et al (1977), mas também podem ser empreendidas por um só componente, que, ao mesmo tempo em que aponta uma fonte de problema, é também um candidato para substituir o item problemático. E, em segundo lugar, observamos que, para além da relação entre o turno com a fonte de problema e o turno de RILCO, é importante observar o terceiro turno na seqüência, para ver como se encerra a seqüência de reparo e se retoma o andamento das ações que o reparo pode ter posto em suspenso. Com relação a esse aspecto, ficou evidente que os participantes se orientam para o fato de que, no terceiro turno da seqüência de RILCO, é o interlocutor reparado quem deve tomar a palavra e, nesse espaço, se vê constrangido a lidar com o fato de que há um problema seu em exposição, seja apresentando uma justificativa para a sua fonte de problema, seja apenas reconhecendo que o item candidato oferecido por seu interlocutor é (mais) adequado. De qualquer modo, a instauração de RILCO cria trabalho interacional para o interlocutor reparado e se configura como mais uma evidência para a despreferência dessa ação em conversa cotidiana. 
Também em consonância com as observações disponíveis na literatura internacional sobre ocorrências de fenômenos de reparo em inglês norteamericano, constatamos, como subproduto de nosso interesse na trajetória de RILCO, que RILCO e discordância se aproximam em termos de sua configuração seqüencial, de modo que, por vezes sua distinção torna-se dificultosa.

Por fim, concluímos que a trajetória de RILCO observada em nossos dados de interações em português brasileiro se apresenta, de modo geral, em conformidade com a descrição do sistema de reparo tal conforme apresentada em Schegloff, Jefferson e Sacks (1977), encarando as diferenças que encontramos entre as descrições já disponíveis na literatura e as nossas observações como avanços na compreensão da organização do sistema de reparo como um todo, da trajetória de RILCO em especial, assim como das ações de corrigir, importantes em si pelas suas implicações para o entendimento da construção do conhecimento e do conflito.

E-mail:pmgarcez@portoweb.com.br Recebido em março de 2005 Aprovado em junho de 2005

\section{REFERÊNCIAS BibLIOGRÁFICAS}

Atkinson, J. Maxwell \& John Heritage. 1984. Structures of Social Action. Cambridge: Cambridge University Press.

Barros, Diana. 1993. Procedimentos de reformulação: a correção. In: D. Preti. Org. Análise de Textos Orais. São Paulo: FFLCH/USP.

Batista, Antônio Augusto G. 1997. Aula de Português: discurso e saberes escolares. São Paulo: Martins Fontes.

CHui, K. 1996. Organization of repair in Chinese conversation. Text, 16(3): 343-372.

Clark, Herbert. 1996. The use of language. In: Using Language. Cambridge: Cambridge University Press. 2000. O uso da linguagem. (Trad. por Nelson de Oliveira Azevedo e Pedro M. Garcez). In: Cadernos de Tradução (UFRGS), 9: 49-71.

Coulon, Alain. 1995. Etnometodologia (Trad. por Ephraim Ferreira Alves). Petrópolis, RJ: Vozes.

Dornelles, Clara \& Pedro M. Garcez. 2001. Making sense of nonsense: fabrication, ambiguity, error and clarification in the organization of 
experience in ordinary conversation. Journal of Pragmatics, 33(11): $1707-$ 1730.

Drew, Paul. 1997. 'Open' class repair initiators in response to sequential sources of troubles in conversation. Journal of Pragmatics, 28: 69-101.

Drew, Paul \& John Heritage. 1992. Talk at Work: interaction in institutional settings. Cambridge: Cambridge University Press.

EGBERT, Maria. 1997. Some interactional achievements of other-initiated repair in multiperson conversation. Journal of Pragmatics, 27: 611-634.

FÁvero, Leonor. 1997. Processos de formulação do texto falado: a correção e a hesitação nas elocuções formais. In: Dino Preti. Org. O Discurso Oral Culto. São Paulo: FFLCH/USP.

FÁvero, Leonor, Maria Lúcia Andrade \& Zilda de Aquino. 1999. Correção no texto falado: tipos, funções e marcas. In: Maria Helena de Moura Neves. Org. Gramática do Português Falado (Vol. VII: 53-76). São Paulo: FAPESP/Humanitas.

FIRTH, Alan. 1996. The discursive accomplishment of "normality": on conversation analysis and "lingua franca" English. Journal of Pragmatics, 27: 237-59.

Garcez, Pedro M. 2002a. Transcrição como teoria: a identificação dos falantes como atividade analítica plena. In: Luiz Paulo da MoITA-LOPES \& Liliana C. BAstos. Orgs. Identidades: recortes inter-e multidisciplinares. Campinas, SP: Mercado de Letras.

. (2002b). Formas institucionais de fala-em-interação e conversa cotidiana: elementos para a distinção a partir da atividade de argumentar. paLavra (PUC-Rio), 8: 54-73.

. (no prelo). A organização da fala-em-interação na sala de aula: controle social, reprodução de conhecimento, construção conjunta de conhecimento. In P. C. Guedes. Org. Ensino de Português e Cidadania. Porto Alegre: Editora da UFRGS.

Garfinkel, Harold. 1967. Studies in Ethnomethodology. Englewood Cliffs, NJ: Prentice Hall.

Gonzalez, Patricia. 2004. Reparo em Terceira Posição na Fala-em-Interação entre Falantes com e sem Afasia de Expressão. Dissertação de mestrado em Letras, UFRGS.

Goodwin, Marjorie H. 1983. Aggravated correction and disagreement in children's conversations. Journal of Pragmatics, 7: 657-677.

Heritage, John. 1984. A change-of-state token and aspects of its sequential placement. In: J. Maxwell Atkinson \& John Heritage. Structures of Social Action. Cambridge: Cambridge University Press. 
. 1987. Ethnomethodology. In: Anthony Giddens \& Jonathan Turner. Orgs. Social Theory Today (pp. 224-272). Stanford, CA: Stanford University Press. Etnometodologia. 1999. (Trad. por Gilson Cesar Cardoso de Souza) In: Anthony Giddens \& Jonathan Turner. Orgs. Teoria Social Hoje (pp. 321-393). São Paulo, Editora da UNESP.

Jacoby, Sally \& Elinor Ochs. 1995. Co-construction: an introduction. Research on Language and Social Interaction, 28(3): 171-183.

Jefferson, Gail. 1987. On exposed and embedded correction in conversation. In: G. Button \& J. R. E. Lee. Orgs. Talk and Social Organisation. Clevedon, Reino Unido: Multilingual Matters.

KurHILA, Salla. 2001. Correction in talk between native and non-native speaker. Journal of Pragmatics, 33: 1083-1110.

Levinson, S. 1983. Pragmatics. Cambridge: Cambridge University Press.

Loder, Letícia L., Patricia C. Gonzalez \& Pedro M. Garcez. 2004. Reparo em terceira posição e intersubjetividade na fala-em-interação em português brasileiro. Veredas (UFJF), 6 (2): 115-122.

Marcuschi, L. A. 1986. Análise da Conversação. São Paulo: Ática.

McHoul, Alec W. 1990. The organization of repair in classroom talk. Language in Society, 19: 349-377.

Moerman, Michael. 1988. Talking Culture: ethnography and conversational analysis. Filadélfia: University of Pennsylvania Press.

Norrick, Neal. 1991. On the organization of corrective exchanges in conversation. Journal of Pragmatics, 16: 59-83.

PomerantZ, Anita. 1984. Agreeing and disagreeing with assessments: some features of preferred and dispreferred turn shapes. In: J. MAxwell Atkinson \& John Heritage. Orgs. Structures of Social Action. Cambridge: Cambridge University Press.

SAcks, Harvey, Emanuel Schegloff \& Gail Jefferson. 1974. A simplest systematics for the organization of turn-taking for conversation. Language, 50: 696-735.

SCHegloff, Emanuel A. 1991. Conversation analysis and socially shared cognition. In: L. Resnick, J. Levine \& S. Teasley. Orgs. Perspectives on Socially Shared Cognition (pp. 150-171). Washington: American Psychological Association.

. 1992a. To Searle on conversation: a note in return. In: John R. Searle, Herman Parrett \& Jef Verschueren. Orgs. (On) Searle on Conversation. Amsterdam/Filadélfia: John Benjamins. 
. 1992b. Repair after next turn: the last structurally provided defense of intersubjectivity in conversation. American Journal of Sociology, 97(5): 1295-1345.

. 1996. Turn organization: one intersection of grammar and interaction. In: Elinor Ochs, Emanuel A. Schegloff \& Sandra A. Thompson. Orgs. Interaction and Grammar. Cambridge: Cambridge University Press.

. 1997a. Practices and actions: boundary cases of other-initiated repair. Discourse Processes, 23: 499-545.

. 1997b. Third-turn repair. In: G. R. Guy, D. Schiffrin \& J. BAugh. Orgs. Towards a Social Science of Language: papers in honor of William Labov. Volume 2: Social interaction and discourse structures. Amsterdam: John Benjamins.

. 1999. Discourse, pragmatics, conversation, analysis. Discourse Studies, 1: 405-435.

. 2000a. When 'others' initiate repair. Applied Linguistics, 21(2): $205-243$.

. 2000b. Overlapping talk and the organization of turn-taking for conversation. Language in Society, 29: 1-63.

. 2003. On dispensability. Research on Language and Social Interaction, 37(2): $95-149$.

Schegloff, Emanuel A., Gail Jefrerson \& Harvey Sacks. 1977. The preference for self-correction in the organization of repair in conversation. Language, 53(2): 361-383.

Wong, Jean. 2000. Delayed next turn repair initiation in native/non-native speaker English conversation. Applied Linguistics, 21(2): 244-267. 


\section{Anexo \\ Principais convenções para transcrição (sistema Gail Jefferson)}

\begin{tabular}{|c|c|c|}
\hline . & (ponto final) & entonação descendente \\
\hline$?$ & (ponto de interrogação) & entonação ascendente \\
\hline , & (vírgula) & entonação de continuidade \\
\hline- & (hífen) & marca de corte abrupto \\
\hline$::$ & (dois pontos) & Prolongamento do som \\
\hline Nunca & (sublinhado) & sílaba ou palavra enfatizada \\
\hline PALAVRA & (maiúsculas) & fala em volume alto \\
\hline${ }^{\circ}$ palavra ${ }^{\circ}$ & (sinais de graus) & fala em voz baixa \\
\hline$>$ palavra $<$ & $\begin{array}{l}\text { (sinais de maior do que e menor } \\
\text { do que) }\end{array}$ & fala acelerada \\
\hline$<$ palavra $>$ & $\begin{array}{l}\text { (sinais de menor do que e maior } \\
\text { do que) }\end{array}$ & fala desacelerada \\
\hline $\mathrm{Hh}$ & (série de h's) & Aspiração ou riso \\
\hline. $\mathrm{hh}$ & (h's precedidos de ponto) & Inspiração audível \\
\hline [ ] $]$ & (colchetes) & fala simultânea ou sobreposta \\
\hline$=$ & (sinais de igual) & Elocuções contíguas \\
\hline$(2,4)$ & (números entre parênteses) & $\begin{array}{l}\text { medida de silêncio (em segundos e } \\
\text { décimos de segundos) }\end{array}$ \\
\hline (.) & (ponto entre parênteses) & micropausa, até $2 / 10$ de segundo \\
\hline$(\quad)$ & (parênteses vazios) & $\begin{array}{l}\text { segmento de fala que não pôde ser } \\
\text { transcrito }\end{array}$ \\
\hline (palavra) & $\begin{array}{c}\text { (segmento de fala entre } \\
\text { parênteses) }\end{array}$ & Transcrição duvidosa \\
\hline $\begin{array}{c}\text { ((olhando para } \\
\text { o teto )) }\end{array}$ & (parênteses duplos) & descrição de atividade não-vocal \\
\hline
\end{tabular}

Adaptado de Atkinson e Heritage (1984:ix-xvi) e das instruções para submissão de artigos ao periódico especializado Research on Language and Social Interaction (Lawrence Erlbaum). 